\title{
Feasible momentum strategies: Evidence from the Swiss stock market
}

\author{
David M. Rey • Markus M. Schmid
}

Published online: 15 May 2007

(C) Swiss Society for Financial Market Research 2007

\begin{abstract}
While there is little controversy on the profitability of momentum strategies, their implementation is afflicted with many difficulties. Most important, chasing momentum can generate high turnover. Though there are already several attempts to make momentum strategies less expensive with respect to transaction costs, we go a step further in the simplification of momentum strategies. By restricting our sample to Switzerland's largest blue-chip stocks and choosing only one winner and one loser stock, we find average returns to our momentum arbitrage portfolios of up to $44 \%$ p.a. depending on the formation and holding periods. While unconditional risk models are at odds with momentum profits, stock market predictability and timevarying expected returns explain a large part of the momentum payoffs, including the post-holding period behavior of the winner and loser stocks (overreaction and subsequent price correction).
\end{abstract}

Keywords Momentum strategies $\cdot$ Large-caps $\cdot$ Event study analysis $\cdot$ Stock market predictability $\cdot$ Under- and overreaction

JEL Classification G11 - G12

\section{Introduction}

A large body of recent finance literature documents that the cross-section of stock returns is predictable based on past returns. For example, DeBondt and Thaler (1985, 1987) report that long-term past loser stocks outperform long-term past winner stocks

D.M. Rey

Department of Finance, University of Basel, Holbeinstrasse 12, 4051 Basel, Switzerland

M.M. Schmid ( $\varangle)$

Swiss Institute of Banking and Finance, University of St. Gallen, 9000 St. Gallen, Switzerland

e-mail: markus.schmid@unisg.ch 
over the subsequent 3 to 5 years. Consistently, the findings of Chopra et al. (1992) suggest that over periods from 1 to 5 years extreme stock market performance tends to reverse itself. Jegadeesh (1990) and Lehmann (1990) find short-term return reversals over periods of one month or less. In contrast, Jegadeesh and Titman (1993) document that over an intermediate horizon of 3 to 12 months, past winner stocks continue to outperform past loser stocks on average. Since then, a large body of empirical literature has confirmed this first evidence on medium-term stock price continuations. Chan et al. (1996), for example, find high profits for momentum strategies based on all stocks listed on NYSE, AMEX, and NASDAQ over the period from January 1977 to January 1993. By sorting stocks based on prior 6-month returns, they find a spread in returns of $8.8 \%$ p.a. between the decile portfolio experiencing the highest past returns and the decile portfolio experiencing the lowest past returns over the subsequent 6 months. Rouwenhorst (1998) documents medium-term return continuation of a similar size for 12 European countries over the period from 1978 to 1995.

Apparently, for long horizons ( 3 to 5 years) and short horizons (1 month or less) stocks tend to mean revert, while there is a continuation in price performance over intermediate horizons ( 3 months to 1 year). What has caught the attention of many investors recently is this predictability of price changes over intermediate horizons. Money managers and stock analysts attempt to exploit this pattern of price momentum. For example, Chen et al. (2000) document that mutual funds typically buy past winner stocks and sell past loser stocks. In addition, Womack (1996) shows that stocks with strong buy recommendations from analysts typically exhibit high price momentum, and stocks with strong sell recommendations typically exhibit low price momentum.

The evaluation of the usefulness of such momentum strategies requires that their profitability is measured. One caveat to bear in mind is that trading is by no means a free activity. Chasing momentum can generate high turnover and much of the potential profits from momentum strategies may be dissipated by transaction costs. Carhart (1997), for example, calculates transaction costs and concludes that momentum is not exploitable after those costs are taken into account. Grinblatt and Moskowitz (2004) note that a large part of the gains associated with momentum strategies are due to short positions in small and illiquid stocks, leading to high transaction costs. They also find that a large part of momentum profits come from short positions taken in November, anticipating tax-loss selling in December. However, they still conclude that momentum profits are large enough to be economically exploitable. In contrast, the findings of Lesmond et al. (2004) suggest that momentum strategies require frequent trading in disproportionately high-cost securities such that trading costs prevent profitable strategy execution. In the cross-section, they find that those stocks that generate large momentum returns are precisely those stocks with high trading costs.

Though there are already several attempts to make momentum strategies less expensive with respect to transaction costs, for example, by restricting the sample to large caps (e.g., see Chan et al. 1999), by excluding stocks with a share price below $\$ 5$ (e.g., see Jegadeesh and Titman 2001), or by concentrating on long and neglecting short positions (e.g., see Grinblatt and Moskowitz 2004), we go a step further in the simplification of momentum strategies. First, we restrict our sample to Switzerland's largest blue-chip stocks contained in the Swiss Market Index (SMI). Since the SMI comprises only 17 to 26 stocks during our sample period from January 1994 to 
December 2004, our strategies do not invest in decile portfolios but in single stocks. Interestingly, arbitrage portfolios investing in only one winner and one loser stock by the same time experience annualized average returns of up to $44 \%$, depending on the length of the formation and holding periods.

We apply different checks on the robustness of our results. By splitting our 11-year sample period into two equal sub-periods of 5.5 years each, we find high returns to our strategies in both sub-periods. Interestingly, momentum returns are higher over the second sub-period which is essentially characterized by a bear market with an average return of roughly $-2 \%$ p.a. for the SMI. The profits of our momentum strategies are also robust to different rebalancing schemes and restricting the strategies from concentrating the investments too strongly. Moreover, we show that the momentum payoffs are not driven by a few individual stocks, but that all stocks in the investment universe contribute to the overall profitability. After all, the profitability of our momentum strategies remains high for reasonable estimates of transaction costs associated with institutional trading in Swiss blue-chip stocks.

While the high profits associated with momentum strategies have been well accepted, the source of these profits and the interpretation of the evidence are still widely debated. We apply various measures of risk including a constant mean, a market, and a two-factor model including a market- and a value/growth-factor. We find our strategy returns to be only slightly reduced on a risk-adjusted basis. However, using a set of lagged macroeconomic variables to predict 1-month-ahead returns, our results suggest that the predicted part of returns can explain a large part of the observed momentum phenomenon.

We also replicate the analysis of Jegadeesh and Titman (2001) and investigate the strategy returns over a 5-year post-holding period to test three alternative hypotheses: (1) underreaction, (2) overreaction and subsequent price correction, and (3) a riskbased explanation put forth by Conrad and Kaul (1998). Our results confirm those of Jegadeesh and Titman (2001) and are consistent with the overreaction and subsequent price correction hypothesis but inconsistent with the risk-based hypothesis of Conrad and Kaul (1998). However, when we consider the residual and systematic return components separately, we again find that cross-sectional differences in conditionally expected returns are able to replicate most of the post-holding period behavior of the winner and loser stocks, respectively.

Our rolling event study analysis also identifies a "contrarian effect" prior to the formation period. In the 2 years before the formation period, cumulative average return differences between the winner and the loser stocks are negative, i.e., loser stock returns are generally higher than the corresponding returns of the winner stocks. In contrast to the (post-) holding period, neither unconditional nor conditional risk models can explain this price behavior prior to the formation period.

The remainder of the paper is organized as follows. Section 2 describes the sample and methodology. Section 3 documents the profitability of the winner and loser portfolios, and the resulting momentum arbitrage strategies, respectively. In Sect. 4, we perform a number of robustness checks. Section 5 assesses the risk and performance of the momentum strategies and reviews theoretical explanations for their profitability. Based on a rolling event study analysis, we also present empirical evidence on the pre-formation and post-holding price behavior of the winner and the loser stocks. Finally, Sect. 6 concludes. 


\section{Sample and methodology}

In contrast to an earlier study on the Swiss stock market by Bacmann and Dubois (2000), our sample includes only stocks contained in the Swiss Market Index (SMI). The SMI is a value-weighted index, unadjusted for dividends. It comprises the highly liquid shares of up to 30 of the most important Swiss large-cap stocks, which represent approximately $80 \%$ of Switzerland's total market capitalization. ${ }^{1}$ As compared to the stocks included in the Swiss Performance index (SPI), consisting of all stocks listed at the Swiss Stock Exchange, SMI stocks are much larger as measured by the market value of equity and experience much higher trading volumes. ${ }^{2}$ To circumvent any survivorship bias in our results and to allow our strategies to choose only stocks which were included in the SMI in any given month, we exactly reconstruct the index based on the official website of the Swiss Stock Exchange (SWX). ${ }^{3}$ This exact replication of the index is important as Chakrabarty and Trzcinka (2006), for example, show that discrepancies in the handling of newly listed and de-listed firms between the CRSP and TAQ databases lead to entirely different conclusions with respect to the profitability of momentum returns.

Our price momentum strategies are based on the stocks' past returns, which are calculated at the end of each month. The winner and loser stocks are selected based on their returns over a formation period of $J=3,6$, or 12 months. The selection process is as follows: We select all stocks on the basis of their past arithmetic mean returns over the formation period $J$ and buy the single stock with the highest past return while, by the same time, the stock with the lowest return is sold short. Stock returns include all cash flows to the stockholders such as dividend payments or nominal share value reductions. For firms with more than one share category included in the SMI, the return calculation is based on the category with the highest market capitalization at the end of the last trading day of the formation period. Likewise, this will be the stock bought or sold short by the strategy. The data used in this study stems from Thomson Financial's Datastream and Kenneth French's Data Library. ${ }^{4}$

We consider holding periods of $K=3,6$, and 12 months. Based on earlier evidence by Jegadeesh (1990), Lehmann (1990), Lo and MacKinlay (1990), and Jegadeesh and Titman (1995), for example, that there is a return reversal for periods shorter than 1 month, we follow the literature (e.g., Grundy and Martin 2001) and introduce a 1-month lag between the holding and formation period. In other words, we skip the first month after portfolio formation and begin with the calculation of portfolio returns one month after the end of the formation period. Again, the calculation of returns accounts for all cash flows to the stock holders such as dividend payments

\footnotetext{
${ }^{1}$ Since October 2001 the stocks in the SMI are weighted according to the companies' free-float market capitalization.

${ }^{2}$ At the end of 2004, the average market value of equity was CHF 28.29bn (CHF 4.01bn) for SMI (SPI) stocks and average monthly trading volume of SMI (SPI) stocks amounted to CHF 1.93bn (CHF 0.25bn). The exclusion of the 27 SMI stocks from the SPI decreases the average market value of equity and the average monthly trading volume to CHF $0.63 \mathrm{bn}$ and CHF $0.02 \mathrm{bn}$, respectively.

${ }^{3}$ The website of the SWX is: www.swx.com.

${ }^{4}$ The website of French's Data Library is: mba.tuck.dartmouth.edu/pages/faculty/ken.french/data_library. html.
} 
and nominal share value reductions. ${ }^{5}$ If a stock was excluded from the SMI after it was included in the winner or loser portfolio, but before the end of the corresponding holding period $K$, it remains in the portfolio until the end of the holding period. In case of mergers during the holding period, the corresponding take-over bid is accepted and possible cash flows are invested at the money market rate until the end of the next regrouping of investments. All cash flows to the stock holders are invested at the prevailing money market rate until the beginning of the following holding period.

Since the holding period $K$ exceeds the interval over which return information is available (monthly), there is an overlap in the holding periods. To increase the power of our tests and to ensure a minimum of diversification, our momentum strategies include portfolios with overlapping holding periods. Each month, thus, $1 / K$ of the holdings is revised. For example, in month $t$, the $J=6 / K=3$ portfolio of winner stocks consists of three investment cohorts: a position carried over from an investment at the end of month $t-3$ in the stock with the highest average return over the respective past 6 months and two positions resulting from investments in the topperforming stocks at the end of months $t-2$ and $t-1$, respectively. At the end of month $t$, the first of these investment cohorts is liquidated and replaced with a new investment in the stock with the highest 6-month average return as of time $t$.

The net asset value (NAV) of each of the $K$ investment cohorts is the sum of a cash position and one long and one short position in the winner and loser stock, respectively. The amount of cash available at the beginning of each holding period defines the size of investment in the winner stock. At the same time, the loser stock is sold short for exactly the same amount, leading to a zero-cost net investment. The cash amount is invested at the prevailing money market rate. The overall NAV of the momentum strategy is then the sum of the NAVs of the $K$ investment cohorts. Because we abstain from leverage (i.e., the cash position is fully invested), the returns to the resulting arbitrage strategies, namely the relative changes of the NAV, are welldefined and easy to interpret. However, these returns cannot be directly compared to those commonly reported in other studies of momentum strategies: First, we report geometric mean returns instead of arithmetic mean returns. Second, the mean returns to our strategies include the interest rate earned on the cash position. Finally, the investment cohorts are not rebalanced every month; a rebalancing only takes place in case of a negative NAV of one (or more) investment cohorts at the end of a month. However, to prevent a too strong divergence in the amount invested in the different investment cohorts, the $K$ different investment cohort are rebalanced annually. Because our momentum strategies invest in only one winner and one loser stock (per investment cohort) and the investment cohorts are not equally weighted every month, the turnover and the number of transactions are much lower in comparison to the momentum strategies commonly discussed in the literature (e.g., see Jegadeesh and Titman 1993). For reasons of comparison, we also report arithmetic mean returns of monthly rebalanced momentum strategies without the cash positions (hereafter referred to as 'zero-cost arbitrage strategies').

\footnotetext{
${ }^{5}$ Our results change only immaterially when dividend payments are ignored. We thus abstain from reporting them in the paper. In more than two-thirds of the strategies (different combinations of $J$ and $K$ ) the average returns to the momentum strategies increase slightly, indicating that loser stocks pay somewhat higher dividends than winner stocks on average.
} 


\section{The returns to feasible momentum strategies}

The annualized mean returns to our price momentum strategies are reported in Table 1 . We consider formation periods of $J=3,6$, and 12 months and holding periods of $K=3,6$, and 12 months, resulting in nine different strategies. The results in Column 1 reveal that the average returns to the arbitrage momentum strategies over the full 11-year period are all positive and range from $9.19 \%$ to $43.79 \%$. Moreover, all values are statistically significant at the $1 \%$ level (with the exception of the $J=3$ / $K=3$ and $J=12$ / $K=3$ strategies, which are significant at the $10 \%$ and $5 \%$ level, respectively). The tests of statistical significance are based on a comparison of the reported strategy returns to Monte Carlo expected returns for a strategy that picks stocks randomly (5000 simulations). Consistent with the findings of prior research, we find the returns to be highest for a formation period of 6 months, whereas they decrease as the length of the holding period increases. The most profitable strategy with a formation period equal to 6 months $(J=6)$ and a holding period equal to three month $(K=3)$ experiences an average return of $43.79 \%$. The second and third best strategies $(J=6 / K=6$ and $J=6 / K=12$, respectively) exhibit mean returns of $26.53 \%$ and $21.88 \%$, respectively. Net asset values for these three strategies along

Table 1 Annualized average returns to arbitrage strategies, zero-cost arbitrage strategies and winner and loser portfolios

\begin{tabular}{|c|c|c|c|c|c|c|c|}
\hline$J$ & $K$ & $\begin{array}{l}\text { Arbitrage } \\
\text { strategy } \\
\text { 1994-2004 } \\
\text { (1) }\end{array}$ & $\begin{array}{l}\text { Zero-cost } \\
\text { arb. strat. } \\
\text { 1994-2004 } \\
\text { (2) }\end{array}$ & $\begin{array}{l}\text { Arbitrage } \\
\text { strategy } \\
\text { 1994-1999:6 } \\
\text { (3) }\end{array}$ & $\begin{array}{l}\text { Zero-cost } \\
\text { arb. strat. } \\
\text { 1994-1999:6 } \\
\text { (4) }\end{array}$ & $\begin{array}{l}\text { Arbitrage } \\
\text { strategy } \\
\text { 1999:7-2004 } \\
(5)\end{array}$ & $\begin{array}{l}\text { Zero-cost } \\
\text { arb. strat. } \\
\text { 1999:7-2004 } \\
\text { (6) }\end{array}$ \\
\hline 3 & 3 & $\begin{array}{l}9.19 \% * \\
(0.0726)\end{array}$ & $\begin{array}{l}13.09 \% \\
(0.2485)\end{array}$ & $\begin{array}{l}4.17 \% \\
(0.3190)\end{array}$ & $\begin{array}{l}4.43 \% \\
(0.4154)\end{array}$ & $\begin{array}{l}14.45 \% * \\
(0.0804)\end{array}$ & $\begin{array}{l}22.41 \% \\
(0.2488)\end{array}$ \\
\hline 3 & 6 & $\begin{array}{l}14.34 \% \text { *** } \\
(0.0066)\end{array}$ & $\begin{array}{l}18.91 \% * * \\
(0.0407)\end{array}$ & $\begin{array}{l}5.47 \% \\
(0.2148)\end{array}$ & $\begin{array}{l}7.63 \% \\
(0.1487)\end{array}$ & $\begin{array}{l}23.95 \% * * * \\
(0.0058)\end{array}$ & $\begin{array}{l}31.27 \% * \\
(0.0521)\end{array}$ \\
\hline 3 & 12 & $\begin{array}{l}12.08 \% * * * \\
(0.0034)\end{array}$ & $\begin{array}{l}13.46 \% * * \\
(0.0409)\end{array}$ & $\begin{array}{l}12.87 \% * * * \\
(0.0014)\end{array}$ & $\begin{array}{l}13.70 \% \\
(0.1491)\end{array}$ & $\begin{array}{l}11.29 \% * \\
(0.0616)\end{array}$ & $\begin{array}{l}13.22 \% \\
(0.2081)\end{array}$ \\
\hline 6 & 3 & $\begin{array}{l}43.79 \% \text { *** } \\
(0.0000)\end{array}$ & $\begin{array}{l}50.87 \% * * * \\
(0.0005)\end{array}$ & $\begin{array}{l}12.89 \% * \\
(0.0586)\end{array}$ & $\begin{array}{l}17.76 \% * * \\
(0.0141)\end{array}$ & $\begin{array}{l}83.15 \% \text { *** } \\
(0.0000)\end{array}$ & $\begin{array}{l}92.32 \% * * * \\
(0.0007)\end{array}$ \\
\hline 6 & 6 & $\begin{array}{l}26.53 \% * * * \\
(0.0000)\end{array}$ & $\begin{array}{l}39.17 \% * * * \\
(0.0025)\end{array}$ & $\begin{array}{l}14.54 \% * * * \\
(0.0076)\end{array}$ & $\begin{array}{l}17.15 \% * * \\
(0.0327)\end{array}$ & $\begin{array}{l}39.76 \% * * * \\
(0.0000)\end{array}$ & $\begin{array}{l}64.92 \% * * * \\
(0.0052)\end{array}$ \\
\hline 6 & 12 & $\begin{array}{l}21.88 \% * * * \\
(0.0000)\end{array}$ & $\begin{array}{l}21.94 \% * * \\
(0.0236)\end{array}$ & $\begin{array}{l}16.78 \% \text { *** } \\
(0.0000)\end{array}$ & $\begin{array}{l}17.56 \% \\
(0.1103)\end{array}$ & $\begin{array}{l}27.20 \% \text { *** } \\
(0.0002)\end{array}$ & $\begin{array}{l}26.47 \% * \\
(0.0918)\end{array}$ \\
\hline 12 & 3 & $\begin{array}{l}15.72 \% * * \\
(0.0128)\end{array}$ & $\begin{array}{l}29.24 \% * * \\
(0.0488)\end{array}$ & $\begin{array}{l}13.06 \% * \\
(0.0594)\end{array}$ & $\begin{array}{l}19.52 \% \\
(0.1644)\end{array}$ & $\begin{array}{l}18.44 \% * \\
(0.0504)\end{array}$ & $\begin{array}{l}39.69 \% \\
(0.1097)\end{array}$ \\
\hline 12 & 6 & $\begin{array}{l}20.10 \% * * * \\
(0.0002)\end{array}$ & $\begin{array}{l}38.26 \% * * \\
(0.0153)\end{array}$ & $\begin{array}{l}19.19 \% \text { *** } \\
(0.0012)\end{array}$ & $\begin{array}{l}26.04 \% * \\
(0.0870)\end{array}$ & $\begin{array}{l}21.02 \% * \\
(0.0134)\end{array}$ & $\begin{array}{l}51.56 \% * \\
(0.0642)\end{array}$ \\
\hline 12 & 12 & $\begin{array}{l}19.75 \% \text { *** } \\
(0.0000)\end{array}$ & $\begin{array}{l}22.35 \% \\
(0.1269)\end{array}$ & $\begin{array}{l}16.15 \% * * * \\
(0.0002)\end{array}$ & $\begin{array}{l}14.30 \% \\
(0.2814)\end{array}$ & $\begin{array}{l}23.47 \% * * * \\
(0.0006)\end{array}$ & $\begin{array}{l}30.92 \% \\
(0.2437)\end{array}$ \\
\hline
\end{tabular}


Table 1 (Continued)

\begin{tabular}{|c|c|c|c|c|c|c|c|}
\hline$J$ & $K$ & $\begin{array}{l}\text { Winner } \\
\text { long } \\
\text { 1994-2004 } \\
(7)\end{array}$ & $\begin{array}{l}\text { Loser } \\
\text { long } \\
\text { 1994-2004 } \\
(8)\end{array}$ & $\begin{array}{l}\text { Winner } \\
\text { long } \\
\text { 1994-1999:6 } \\
\text { (9) }\end{array}$ & $\begin{array}{l}\text { Loser } \\
\text { long } \\
\text { 1994-1999:6 } \\
(10)\end{array}$ & $\begin{array}{l}\text { Winner } \\
\text { long } \\
\text { 1999:7-2004 } \\
(11)\end{array}$ & $\begin{array}{l}\text { Loser } \\
\text { long } \\
\text { 1999:7-2004 } \\
(12)\end{array}$ \\
\hline 3 & 3 & $\begin{array}{l}6.94 \% \\
(0.4002)\end{array}$ & $\begin{array}{l}-10.27 \% \text { *** } \\
(0.0028)\end{array}$ & $\begin{array}{l}15.50 \% \\
(0.6602)\end{array}$ & $\begin{array}{l}12.13 \% \\
(0.1498)\end{array}$ & $\begin{array}{l}-0.98 \% \\
(0.2876)\end{array}$ & $\begin{array}{l}-28.19 \% \text { *** } \\
(0.0048)\end{array}$ \\
\hline 3 & 6 & $\begin{array}{l}11.24 \% * \\
(0.0896)\end{array}$ & $\begin{array}{l}-8.70 \% \text { *** } \\
(0.0008)\end{array}$ & $\begin{array}{l}17.62 \% \\
(0.5592)\end{array}$ & $\begin{array}{l}11.22 \% * * \\
(0.0392)\end{array}$ & $\begin{array}{l}5.21 \% * \\
(0.0464)\end{array}$ & $\begin{array}{l}-25.05 \% \text { *** } \\
(0.0024)\end{array}$ \\
\hline 3 & 12 & $\begin{array}{l}10.11 \% \\
(0.1078)\end{array}$ & $\begin{array}{l}-2.69 \% * * * \\
(0.0016)\end{array}$ & $\begin{array}{l}22.95 \% * \\
(0.0692)\end{array}$ & $\begin{array}{l}9.40 \% * * * \\
(0.0008)\end{array}$ & $\begin{array}{l}-1.39 \% \\
(0.2860)\end{array}$ & $\begin{array}{l}-13.45 \% * * \\
(0.0268)\end{array}$ \\
\hline 6 & 3 & $\begin{array}{l}26.19 \% * * * \\
(0.0002)\end{array}$ & $\begin{array}{l}-15.99 \% * * * \\
(0.0004)\end{array}$ & $\begin{array}{l}22.27 \% \\
(0.2370)\end{array}$ & $\begin{array}{l}2.15 \% * * * \\
(0.0018)\end{array}$ & $\begin{array}{l}30.24 \% * * * \\
(0.0002)\end{array}$ & $\begin{array}{l}-30.90 \% \text { *** } \\
(0.0018)\end{array}$ \\
\hline 6 & 6 & $\begin{array}{l}18.03 \% \text { \%** } \\
(0.0004)\end{array}$ & $\begin{array}{l}-16.61 \% * * * \\
(0.0000)\end{array}$ & $\begin{array}{l}20.24 \% \\
(0.3152)\end{array}$ & $\begin{array}{l}2.44 \% * * * \\
(0.0000)\end{array}$ & $\begin{array}{l}15.86 \% * * * \\
(0.0002)\end{array}$ & $\begin{array}{l}-32.12 \% \text { *** } \\
(0.0000)\end{array}$ \\
\hline 6 & 12 & $\begin{array}{l}15.29 \% \text { *** } \\
(0.0006)\end{array}$ & $\begin{array}{l}-4.42 \% * * * \\
(0.0004)\end{array}$ & $\begin{array}{l}23.36 \% * \\
(0.0534)\end{array}$ & $\begin{array}{l}4.87 \% * * * \\
(0.0000)\end{array}$ & $\begin{array}{l}7.74 \% * * * \\
(0.0016)\end{array}$ & $\begin{array}{l}-12.89 \% * * \\
(0.0362)\end{array}$ \\
\hline 12 & 3 & $\begin{array}{l}11.36 \% \\
(0.1232)\end{array}$ & $\begin{array}{l}-14.55 \% * * * \\
(0.0004)\end{array}$ & $\begin{array}{l}23.74 \% \\
(0.1676)\end{array}$ & $\begin{array}{l}1.66 \% * * * \\
(0.0012)\end{array}$ & $\begin{array}{l}0.22 \% \\
(0.2276)\end{array}$ & $\begin{array}{l}-28.18 \% \text { *** } \\
(0.0032)\end{array}$ \\
\hline 12 & 6 & $\begin{array}{l}12.73 \% * * \\
(0.0324)\end{array}$ & $\begin{array}{l}-22.26 \% * * * \\
(0.0000)\end{array}$ & $\begin{array}{l}26.35 \% * * \\
(0.0292)\end{array}$ & $\begin{array}{l}-1.79 \% * * * \\
(0.0000)\end{array}$ & $\begin{array}{l}0.58 \% \\
(0.1732)\end{array}$ & $\begin{array}{l}-38.46 \% \text { *** } \\
(0.0000)\end{array}$ \\
\hline 12 & 12 & $\begin{array}{l}8.39 \% \\
(0.2368)\end{array}$ & $\begin{array}{l}-9.35 \% * * * \\
(0.0000)\end{array}$ & $\begin{array}{l}21.52 \% \\
(0.1702)\end{array}$ & $\begin{array}{l}3.28 \% * * * \\
(0.0000)\end{array}$ & $\begin{array}{l}-3.31 \% \\
(0.3910)\end{array}$ & $\begin{array}{l}-20.43 \% \text { *** } \\
(0.0008)\end{array}$ \\
\hline
\end{tabular}

Table 1 reports annualized mean returns to momentum arbitrage strategies and the winner and loser portfolios for different combinations of the formation period $J$ and holding period $K$. The arbitrage strategies (Columns 1, 3, and 5) consist of a long position in one winner, a short position of equal size in one loser stock, and the corresponding cash positions. The $K$ different investment cohorts are rebalanced annually. The zero-cost arbitrage strategies (Columns 2, 4, and 6) consist of a long position in one winner and a short position of equal size in one loser stock and are rebalanced monthly. The average returns to the winner and loser portfolios are based on long positions only, and the $K$ different investment cohorts are rebalanced annually. The table reports annualized geometric mean returns to arbitrage strategies (Columns 1 , 3 , and 5) and strategies based on long positions in winner or loser portfolios (Columns 7 to 12), and annualized arithmetic mean returns to zero-cost arbitrage strategies (Columns 2, 4, and 6). The results are based on the full sample period from 1994 to 2004 and two sub-periods of equal length (1994-1999:6, 1999:7-2004). Tests of statistical significance compare actual values to expected values for a strategy that picks stocks randomly and are based on Monte Carlo simulations (5000 simulations). The evaluation of the statistical significance of the zero-cost arbitrage strategies is based on conventional (two-sided) $t$-tests

$* * * I^{* *} / *$ Denotes statistical significance at the $1 \% / 5 \% / 10 \%$ level ( $p$-values are in parentheses)

with the SMI are displayed graphically in Fig. 1a. In the subsequent analysis we often concentrate on these three strategies.

In general, our results reveal that the returns to our cost-saving feasible momentum strategies are comparable to those reported in earlier research allowing the strategies to choose from a much larger sample of stocks including illiquid and high-cost smallcaps. For example, Chan et al. (1999) report similar results for the U.S., Schiereck et al. (1999) for the German stock market, and Rouwenhorst (1998) for 12 different 
(a) NAVs of Arbitrage Strategies and SMI

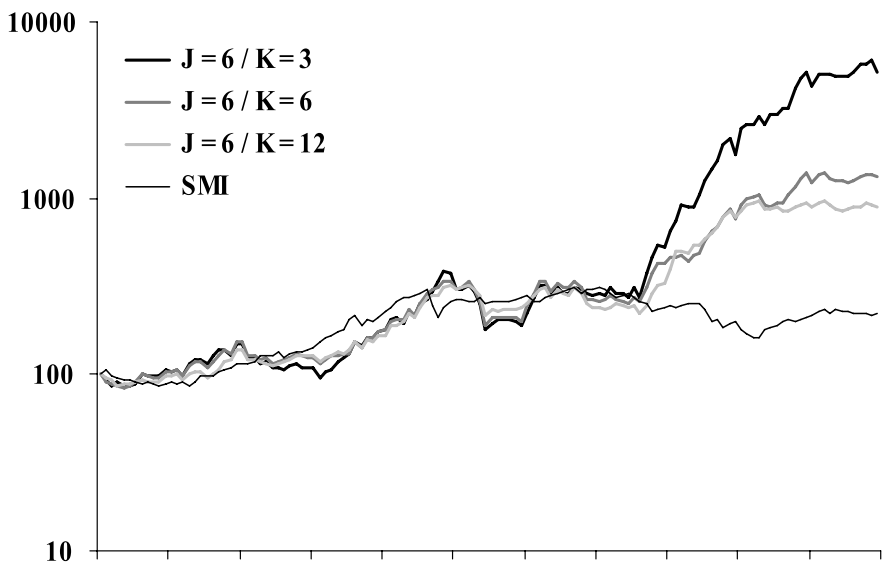

19941995199619971998199920002001200220032004

(b) Cumulative Realized Gains and Losses

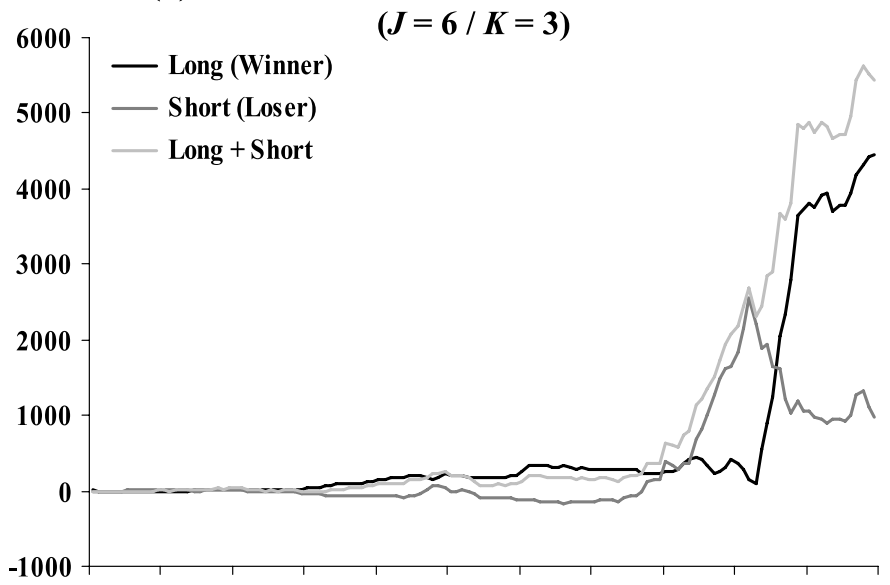

19941995199619971998199920002001200220032004

Fig. 1 Net Asset Value (NAV) of the zero-cost arbitrage strategies and cumulative realized gains and losses from the long (winner stocks) and short (loser stocks) positions. (a) displays the (log) Net Asset Value (NAV) for the three most profitable combinations of $J$ and $K(J=6 / K=3, J=6 / K=6$, and $J=6 / K=12$ ) along with the Swiss Market Index (SMI, including dividend payments); December $1993=100$. (b) to (d) plot the cumulative realized gains and losses from the long (winner stocks) and short (loser stocks) positions, respectively, for the $J=6 / K=3$ strategy (b), the $J=6 / K=6$ strategy (c), and the $J=6 / K=12$ strategy (d)

European countries. ${ }^{6}$ If anything, the returns to our momentum strategies are higher. This is especially surprising because Lesmond et al. (2004) show that the momentum

\footnotetext{
${ }^{6}$ Interestingly, Rouwenhorst's (1998) sample also includes Switzerland. For a formation period of 6 months and a holding period of 6 months, he reports an annual mean return of $7.68 \%$ for the Swiss arbitrage portfolio consisting of a long position in the decile portfolio of past winners and a short position in the decile portfolio of past losers over the period from 1980 to 1995.
} 
(c) Cumulative Realized Gains and Losses

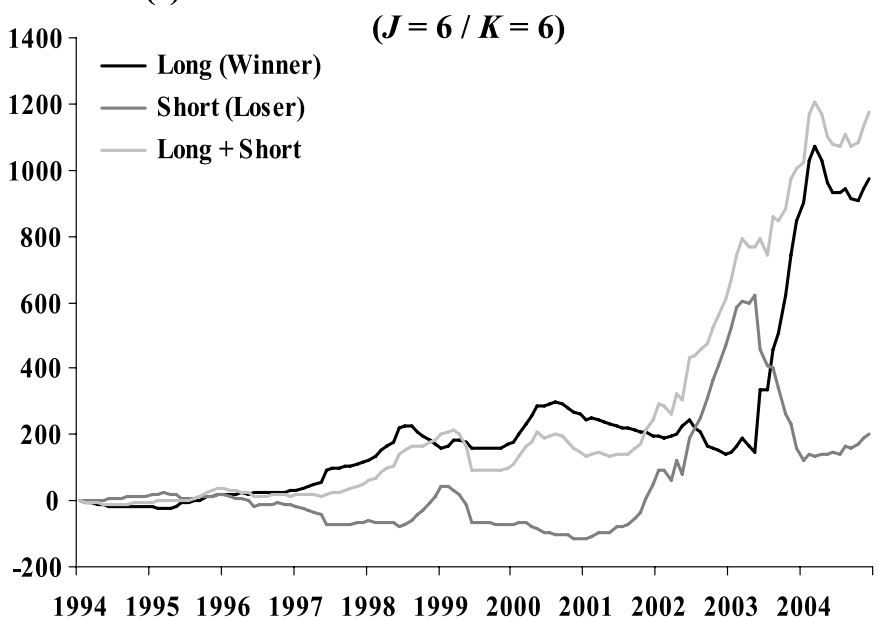

(d) Cumulative Realized Gains and Losses

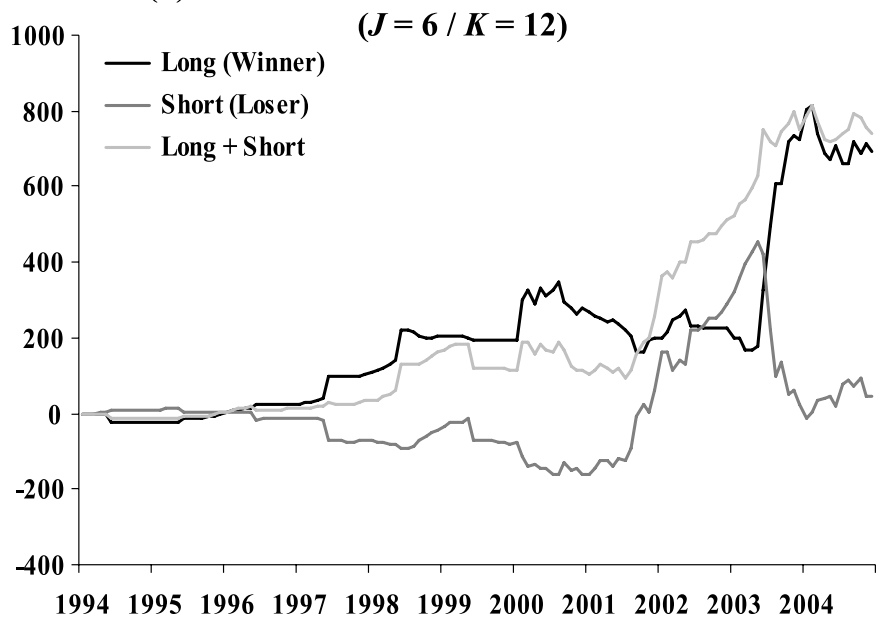

Fig. 1 (Continued)

portfolios, and particularly the loser portfolio that generates the majority of the total strategy abnormal return, are comprised of stocks that can be characterized as small, low price, high beta, off-NYSE stocks. ${ }^{7}$ In contrast, our results reveal that even very basic momentum strategies, consisting of long and short positions in only one single Swiss blue-chip stock, yield average returns which are comparable to or even higher

\footnotetext{
${ }^{7}$ Notice that trading in low-price stocks increases trading costs. Thus, the finding that momentum strategies tend to choose small and low-price stocks are two different, albeit related, concerns. However, our sample is not afflicted with that problem. The average (median) stock price over the full sample period is CHF 1512.79 (CHF 1193.08) which approximately corresponds to US\$ 1210.23 (US\$ 954.46) based on the December 2004 exchange rate of CHF 1.25 per US\$. The minimum stock price over all stocks and sample months is CHF 1.56 (ABB, end of October 2002).
} 
than those of earlier research allowing their strategies to choose from all stocks listed at NYSE, AMEX, and NASDAQ and investing in the winner and loser deciles.

Column 2 of Table 1 reports the arithmetic mean returns to zero-cost arbitrage momentum strategies which are comparable to those analyzed in prior research (i.e., monthly rebalanced strategies without cash positions). As expected, arithmetic mean returns are generally higher than the reported geometric mean returns and, based on conventional (two-sided) $t$-tests, are still statistically significant at the $5 \%$ level or better (with the exception of the $J=3 / K=3$ and the $J=12 / K=12$ strategies).

Columns 3 and 5 report geometric mean returns to our standard arbitrage strategies and Columns 4 and 6 arithmetic mean returns to the zero-cost arbitrage strategies for two sub-periods of equal length. The first sub-period from January 1994 to June 1999 is characterized by a strong bull market, the second sub-period from July 1999 to December 2004 by a bear market: The average returns to the SMI (including dividend payments) for the two sub-periods are $18.74 \%$ and $-1.99 \%$ p.a., respectively. The results in Column 3 (4) reveal that over the first sub-period, the profitability of the (zero-cost) arbitrage portfolios is substantially lower than over the full period. However, the returns to the momentum strategies remain positive and for the standard arbitrage strategies statistically significant at the $10 \%$ level or better (with the exception of the $J=3 / K=3$ and the $J=3 / K=6$ strategies). The three strategies identified as the most profitable over the full sample period (i.e., the $J=6 / K=3$, the $J=6 / K=6$, and the $J=6 / K=12$ strategies) still experience mean returns between $12.89 \%$ and $16.78 \%$ (Column 3 ) and $17.15 \%$ and $17.76 \%$ (Column 4), respectively. Column 5 (6) shows that over the second sub-period, mean returns are significantly higher and range between $27.20 \%$ and $83.15 \%$ p.a. $(26.47 \%$ and $92.32 \%$ p.a.) for these three strategies. In general, the results indicate that our feasible price momentum strategies are more profitable in volatile down markets than in up markets. Nevertheless, the returns to the most promising strategies still remain high and are economically significant even in a less volatile bull market. These finding are at odds with those of Chordia and Shivakumar (2002), who find the returns to their momentum strategies to be positive only during expansionary periods and negative during recessions (see also Footnote 11).

Columns 7 and 8 of Table 1 report the geometric mean returns to the winner and loser portfolios over the full sample period from 1994 to 2004. The winner and loser portfolios are based on long positions only and the $K$ different investment cohorts are rebalanced annually. The results reveal that the mean returns to the winner portfolios are all positive and those to the loser portfolios all negative. Columns 9 and 10 report the geometric mean returns to the winner and loser portfolios over the first sub-period, and Columns 11 and 12 over the second sub-period, respectively. Given the bull market over the first and the bear market over the second sub-period, it is not surprising that the average returns to the winner and loser portfolios are in general higher over the first sub-period as compared to the second sub-period. For example, for the three most profitable strategies, the average mean return to the winner (loser) portfolio is $21.96 \%(3.15 \%)$ p.a. over the first sub-period, and $17.95 \%(-25.30 \%)$ p.a. over the more recent sub-period.

Hong et al. (2000), Jegadeesh and Titman (2001), and Lesmond et al. (2004), for example, find that the majority of the momentum returns is generated by the short 
positions. Despite the fact that the mean returns to the loser portfolios over the full sample period are negative, our results do not confirm their findings. Figures $1 \mathrm{~b}$ to $1 \mathrm{~d}$ plot the cumulative realized gains and losses from the long (winner stocks) and short (loser stocks) positions, respectively. The contributions of the short positions (loser stocks) to the profitability of the arbitrage strategies are negative over the first subperiod. Given the positive mean returns of the loser stocks over this period, this is of course expected. However, in comparison with the contributions of the long positions (winner stocks), the contributions of the short positions are modest even over the full sample period. Most of the high profits in the years 2001 and 2002 vanish in 2003. Hence, besides providing the necessary funds for the long positions in the winner stocks, the short positions do not contribute substantially to the high profitability of the arbitrage strategies on average.

\section{Robustness checks}

The results of the last section reveal surprisingly high returns to our simple and costsaving momentum strategies based exclusively on Swiss blue-chip stocks. Specifically, the three most profitable arbitrage strategies experience average returns between $21.88 \%$ and $43.79 \%$ over the 11-year sample period from January 1994 to December 2004. In this section, we perform several checks on the robustness of these results.

\subsection{Formation period returns, rebalancing, and the concentration of investments}

As a starting point, we recalculate the returns to the arbitrage strategies when the selection of stocks into the winner and loser portfolio is based on their geometric instead of arithmetic mean returns over the formation period. The results are reported in Column 2 of Table 2. For ease of comparison, Column 1 reproduces the results for the standard arbitrage strategy as reported in Column 1 of Table 1 . The average returns to the nine different $J / K$-combinations are somewhat reduced, but the results remain qualitatively similar. The three $J=6 / K=3, J=6 / K=6$, and $J=6$ / $K=12$ strategies still experience mean returns ranging from $11.50 \%$ to $33.33 \%$, and are all statistically significant at the $1 \%$ level.

We also investigate the impact on the average returns to the momentum strategies when the annual rebalancing of the investment cohorts is omitted. On average, the results in Column 3 reveal a slight reduction of the mean returns as compared to Column 1. However, the average returns are somewhat higher than those reported in Column 2, and, with one exception (the $J=3 / K=3$ strategy), all are statistically significant at the $5 \%$ level or better.

The selection procedure described in Sect. 2 allows our strategies to invest more than one investment cohort in the same stock. For example, if in month $t$ the same stock experiences the highest arithmetic mean return over the formation period $J$ as in month $t-1$, two out of $K$ investment sequences are long in the same stock. By the same logic, it is possible that over certain periods of time our momentum strategies consist of long positions in only one single stock and short positions in only one 
(albeit another) stock. ${ }^{8}$ Column 4 of Table 2 shows the results for momentum strategies that are restricted from investing more than one investment cohort in the same stock. ${ }^{9}$ Specifically, the strategy buys (sells short) the second best (worst) performer

Table 2 Checks on the robustness of momentum returns

Annualized (geometric) mean returns for different combinations of $J$ and $K$

\begin{tabular}{|c|c|c|c|c|c|}
\hline$J$ & $K$ & $\begin{array}{l}\text { Standard } \\
\text { arbitrage strategy } \\
\text { (1) }\end{array}$ & $\begin{array}{l}\text { Geom. mean returns } \\
\text { over formation period } \\
\text { (2) }\end{array}$ & $\begin{array}{l}\text { No annual } \\
\text { rebalancing } \\
\text { (3) }\end{array}$ & $\begin{array}{l}\text { Investment cohorts } \\
\text { are diversified } \\
\text { (4) }\end{array}$ \\
\hline 3 & 3 & $\begin{array}{l}9.19 \% * \\
(0.0726)\end{array}$ & $\begin{array}{l}4.30 \% \\
(0.2222)\end{array}$ & $\begin{array}{l}7.22 \% \\
(0.1358)\end{array}$ & $\begin{array}{l}7.81 \% \\
(0.1082)\end{array}$ \\
\hline 3 & 6 & $\begin{array}{l}14.34 \% * * * \\
(0.0066)\end{array}$ & $\begin{array}{l}11.87 \% * * \\
(0.0204)\end{array}$ & $\begin{array}{l}14.25 \% \text { \%** } \\
(0.0060)\end{array}$ & $\begin{array}{l}7.41 \% * \\
(0.0952)\end{array}$ \\
\hline 3 & 12 & $\begin{array}{l}12.08 \% * * * \\
(0.0034)\end{array}$ & $\begin{array}{l}7.60 \% * \\
(0.0536)\end{array}$ & $\begin{array}{l}15.10 \% * * * \\
(0.0004)\end{array}$ & $\begin{array}{l}4.68 \% \\
(0.1822)\end{array}$ \\
\hline 6 & 3 & $\begin{array}{l}43.79 \% * * * \\
(0.0000)\end{array}$ & $\begin{array}{l}33.33 \% * * * \\
(0.0000)\end{array}$ & $\begin{array}{l}36.12 \% * * * \\
(0.0000)\end{array}$ & $\begin{array}{l}18.93 \% * * * \\
(0.0048)\end{array}$ \\
\hline 6 & 6 & $\begin{array}{l}26.53 \% * * * \\
(0.0000)\end{array}$ & $\begin{array}{l}18.17 \% \text { *** } \\
(0.0008)\end{array}$ & $\begin{array}{l}21.18 \% * * * \\
(0.0000)\end{array}$ & $\begin{array}{l}3.56 \% \\
(0.2824)\end{array}$ \\
\hline 6 & 12 & $\begin{array}{l}21.88 \% * * * \\
(0.0000)\end{array}$ & $\begin{array}{l}11.50 \% \text { \%** } \\
(0.0056)\end{array}$ & $\begin{array}{l}19.80 \% \text { *** } \\
(0.0000)\end{array}$ & $\begin{array}{l}1.66 \% \\
(0.4712)\end{array}$ \\
\hline 12 & 3 & $\begin{array}{l}15.72 \% * * \\
(0.0128)\end{array}$ & $\begin{array}{l}14.69 \% * * \\
(0.0184)\end{array}$ & $\begin{array}{l}12.19 \% * * \\
(0.0414)\end{array}$ & $\begin{array}{l}-1.67 \% \\
(0.5516)\end{array}$ \\
\hline 12 & 6 & $\begin{array}{l}20.10 \% * * * \\
(0.0002)\end{array}$ & $\begin{array}{l}15.97 \% * * * \\
(0.0026)\end{array}$ & $\begin{array}{l}15.33 \% * * * \\
(0.0026)\end{array}$ & $\begin{array}{l}3.73 \% \\
(0.2632)\end{array}$ \\
\hline 12 & 12 & $\begin{array}{l}19.75 \% * * * \\
(0.0000)\end{array}$ & $\begin{array}{l}7.86 \% * * \\
(0.0472)\end{array}$ & $\begin{array}{l}14.71 \% \text { *** } \\
(0.0006)\end{array}$ & $\begin{array}{l}1.16 \% \\
(0.4966)\end{array}$ \\
\hline
\end{tabular}

Table 2 reports annualized (geometric) mean returns to arbitrage strategies when the selection of stocks over the formation period is based on geometric instead of arithmetic mean returns (Column 2), the annual rebalancing is omitted (Column 3), and the strategy is restricted from investing more than one investment cohort in the same stock (Column 4). For ease of comparison, Column 1 reproduces the results for the standard arbitrage strategy as reported in Column 1 of Table 1. Arbitrage portfolios consist of a long position in one winner, a short position of equal size in one loser stock, and the corresponding cash positions. The results are based on the full sample period from 1994 to 2004. Tests of statistical significance compare actual values to expected values for a strategy that picks stocks randomly and are based on Monte Carlo simulations (5000 simulations)

$* * * * * *$ Denotes statistical significance at the $1 \% / 5 \% / 10 \%$ level ( $p$-values are in parentheses)

\footnotetext{
${ }^{8}$ For example, the three different investment cohorts of the $J=6, K=3$ strategy are long in three different stocks in $19.70 \%$ of the months, in two different stocks in $49.24 \%$ of the months, and in one single stock in $31.06 \%$ of the 132 sample months. The holdings in the short positions are somewhat less concentrated: The respective number for three different, two different, and one single stock are $21.21 \%, 62.88 \%$, and $15.91 \%$, respectively.

${ }^{9}$ Theoretically, due to the staggered formation periods associated with the different investment cohorts, it is even possible that the arbitrage strategy has a long and short position in the same stock at the same time. However, if at all, this constellation is rather unlikely to occur at regular intervals. Hence, we abstain
} 
or in general the next best (worst) stock not yet included as a long (short) position in another investment cohort. The results reveal that this restriction has a substantial negative effect on the strategy returns. As expected, the reduction in strategy returns increases in $J$ and $K$ in general. Most important, the results in Column 4 indicate that the momentum effect-at least for Swiss blue-chip stocks-is substantially stronger between the single best and worst performer than between the second or third best and worst performers over the formation period. These results are confirmed by Fig. 2a, which displays the annualized geometric mean return to the arbitrage strategies that are based on the $n$th best and $n$th worst performing stocks, for $n=1,2, \ldots, 5$. For the three most profitable combinations of $J$ and $K$, it becomes evident that the strategy returns decrease substantially as $n$ increases. Figure $2 \mathrm{~b}$ displays the annualized (geometric) mean returns to an arbitrage strategy investing not in one single winner and loser stock (per investment cohort), but in a portfolio of the $n=1,2, \ldots, 5$ best (winner) and worst (loser) past performers. The $n$ parallel investment cohorts are rebalanced at the end of each holding period. Most important, the figure reveals that the returns decrease in $n$, once more confirming that the momentum effect is substantially stronger between the single best and worst performer than between the second, third, $\ldots, n$th best and worst performers over the formation period. ${ }^{10}$

\subsection{Are momentum returns generated by some few months with extreme returns or} a few individual stocks?

In a next step, we examine whether our results are generated by some few months with extreme return values. We begin this robustness check by replacing the $p$ highest monthly holding period returns for the winner stocks and the $p$ lowest returns for the loser stocks by zero for $p=1,2$ and 3. Although the returns decrease monotonically in $p$ by construction, the returns to all arbitrage portfolios remain positive and statistically significant at the $5 \%$ level or better (with the exception of the $J=3$ / $K=3$ strategy and the $J=12 / K=3$ strategy for $p=2$ and 3 ). Furthermore, the three most profitable strategies $(J=6 / K=3, J=6 / K=6$, and $J=6 /$ $K=12$ ) still experience substantial average returns between $19.30 \%$ and $38.58 \%$ for $p=1,16.72 \%$ and $35.59 \%$ for $p=2$, and $15.95 \%$ and $32.19 \%$ for $p=3$, respectively. For the sake of brevity, we abstain from reporting the complete results in a table. We also replace the $p$ highest and lowest monthly winner and loser stock returns by zero. Here the ex ante expected effect on the momentum returns is less clear. In fact, the results (not reported in a table) reveal an ambiguous effect on average returns. In general, average returns remain qualitatively similar to those reported in Column 1 of Table 1, indicating that the deletion of the highest monthly winner

\footnotetext{
from introducing an additional restriction preventing long positions in a stock, in which another investment cohort already holds a short position and vice versa.

${ }^{10}$ We also test how the results change when the 1-month time lag between formation and holding period is omitted: As expected, the strategy returns decrease as compared to the standard strategy (with the exception of the $J=12, K=6$ strategy). For example, the returns to the three most profitable strategies are $19.20 \%$ $(J=6, K=3), 24.13 \%(J=6, K=6)$, and $20.61 \%(J=6, K=12)$. However, it is important to note that omitting the 1-month lag between the formation and holding period is problematic as both the portfolio decision and the implementation have to be accomplished at the same time, and therefore, the strategies are not feasible anymore.
} 
(a) Single-Stock Arbitrage Strategies

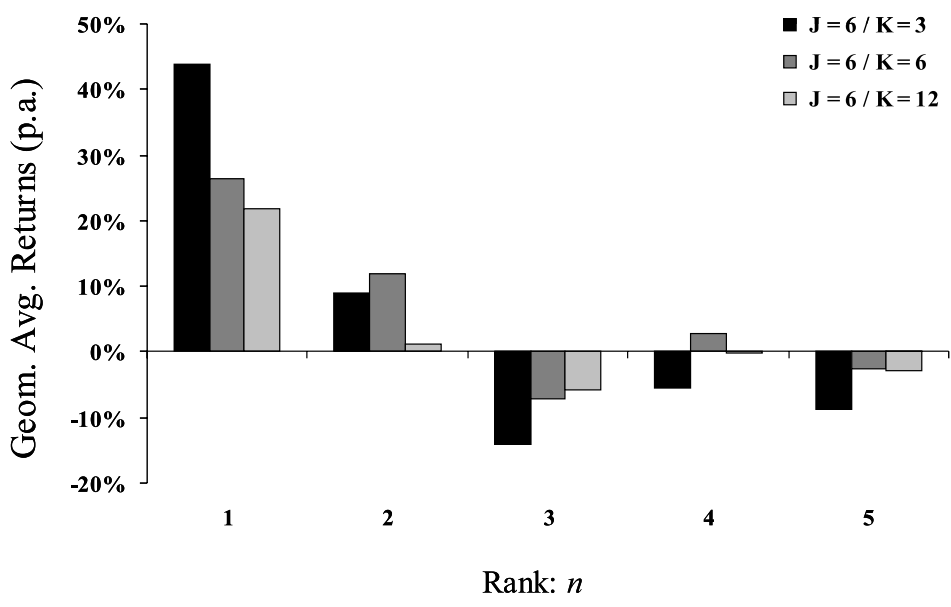

(b) Portfolio Arbitrage Strategies

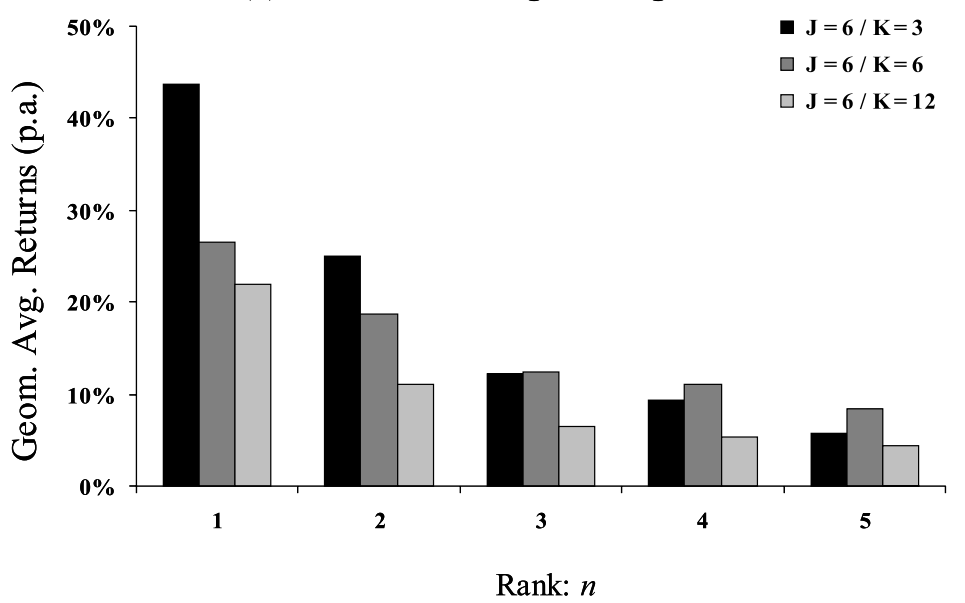

Fig. 2 Annualized average returns to the arbitrage strategies based on the $n$th best and $n$th worst past performers. (a) Displays the annualized (geometric) mean returns to arbitrage strategies based on the $n$th best (winner) and $n$th worst (loser) past performers for $n=1,2, \ldots, 5$. (b) Displays the annualized (geometric) mean returns to an arbitrage strategy investing not in one single winner and loser stock (per investment cohort), but in a portfolio of the $n=1,2, \ldots, 5$ best (winner) and worst (loser) past performers. Black represents the $J=6 / K=3$ strategy, dark gray the $J=6 / K=6$ strategy, and light gray the $J=6$ / $K=12$ strategy, respectively

and lowest monthly loser stock returns seems to be outweighed by the deletion of the lowest monthly winner and highest monthly loser stock returns. In other words, the contribution of extreme return values to strategy returns seems to be similar for winner and loser stocks.

We also investigate whether the high returns to our momentum strategies are generated by a few individual stocks in our sample. We conduct this analysis by calculating the return to the strategies when each individual stock is excluded from the 
sample. Over the full sample period from 1994 to 2004, 35 different stocks were included in the SMI and hence could be chosen by our strategies. In short, the results (not reported in a table) reveal that the mean/median return values for the full sample period and the two sub-periods from 1994 to 1999:6 and from 1999:7 to 2004 are very close to the return values for the unrestricted sample.

\subsection{Transaction costs}

A number of studies investigate the effects of trading costs on momentum (and contrarian) strategies. Ball et al. (1995), for example, show that market microstructure effects, such as bid-ask spreads, significantly reduce the profitability of contrarian strategies. Grundy and Martin (2001) find that the profits to their momentum strategies become statistically insignificant at round-trip transaction costs of roughly $1.50 \%$. At round-trip transaction costs of $1.77 \%$, the profits to their momentum strategies are driven to zero. Korajczyk and Sadka (2004) investigate the effects of trading costs, including the price impact of the trades, on the profitability of momentum strategies. Specifically, they employ several trading cost models and momentum strategies and find that the estimated excess returns to some momentum strategies disappear only after US\$ 4.5 to over US\$ 5.0 billion (relative to the market capitalization in December 1999) is engaged by a single fund in such strategies. They conclude that momentum strategies are robust to transaction costs in the form of spreads as well as price impacts of trades. Lesmond et al. (2004), in contrast, find that standard price momentum strategies require frequent trading in disproportionately high cost securities such that trading costs prevent profitable strategy execution. They conclude that the magnitude of the abnormal returns associated with their momentum strategies creates an illusion of profit opportunity when, in fact, none exists.

We attempt to analyze the sensitivity of our strategy returns to trading costs by subtracting a fixed percentage from the monthly stock returns in those months where a transaction occurs. While this simple approximation accounts for the dynamics of the trading strategy by incorporating the transaction costs when they in fact occur, it neither considers market frictions induced by trading (i.e., a price impact) nor attempts to account for potential differences in trading costs associated with different stocks or stock characteristics. For simplicity, we assume that transaction costs for buying and selling winner stocks as well as selling short and buying back loser stocks are of equal size.

Our results (not reported in table) reveal that for transaction costs of 138, 122, and 156 basis points, the mean returns to the $J=6 / K=3, J=6 / K=6$, and $J=6 / K=12$ strategies, respectively, cease to be statistically significant at the $5 \%$ significance level. At transaction costs of 194, 206, and 241 basis points, respectively, the momentum returns are driven to zero. When we account for the higher transaction costs associated with short sales by doubling the costs to each transaction in the loser stocks, the figures are 92, 81, and 104 basis points in the first case, and 129, 140, and 161 basis points in the second case, respectively.

We acknowledge that the preceding analysis provides only a crude approximation to the effect of transaction costs on the profitability of our momentum strategies. However, given that our momentum strategies invest only in Switzerland's largest and most liquid blue-chip stocks, transaction costs (and possible price effects induced 
by the trades) are likely to be small, especially as compared to the values estimated in prior research allowing the strategies to invest in a much larger number of stocks, such as all stocks listed at NYSE, AMEX, and NASDAQ or the CRSP universe, for example. Hence, we conclude that our feasible momentum strategies remain highly profitable also when transaction costs are accounted for.

\section{Explanations for the profitability of momentum strategies}

Although the high profits associated with momentum strategies have been well accepted, the source of these profits and the interpretation of the evidence are widely debated. Basically, there are three different approaches to explain the profitability of momentum strategies: (1) the documented returns may be the product of data mining, (2) the returns from momentum strategies may be a compensation for risk, and (3) momentum profits may be due to market inefficiencies.

\subsection{Data mining}

The criticism that observed empirical regularities are due to data mining is typically the hardest to address as empirical research (in non-experimental settings) is limited by data availability. However, since the original work of Jegadeesh and Titman (1993) based on a U.S. sample from 1965 to 1989, a large body of research has confirmed their findings for other countries as well as different time periods. For example, Jegadeesh and Titman (2001) use U.S. data from 1990 to 1998 to perform an out-ofsample test of their momentum strategies and find the profitability to be virtually unchanged. Rouwenhorst (1998) documents similar medium-term return continuation for 12 European countries over the period from 1978 to 1995. Schiereck et al. (1999) find significant returns to momentum strategies in Germany. Hence, against the background of this overwhelming empirical evidence supporting the profitability of momentum strategies, there is little doubt about the profitability of these strategies meanwhile and it is widely accepted that the high returns are unlikely to be due to data mining.

\subsection{Risk-based explanations}

There are various risk-based explanations for the profitability of momentum strategies. Conrad and Kaul (1998), for example, argue that stocks with high (low) realized returns are those that have high (low) expected returns suggesting that the momentum strategies' profitability is a result of cross-sectional variability in expected returns. However, Jegadeesh and Titman (2001) argue that reversals in the post-holding period reject the claim of Conrad and Kaul (1998) that momentum profits are generated by a dispersion in unconditionally expected returns. Moreover, they argue that the results of Conrad and Kaul (1998) are driven by estimation errors in the estimation of the expected return variance. Grundy and Martin (2001) investigate the dynamic factor exposure of momentum strategies. They show that the strategies' average profitability cannot be explained as a reward for bearing the dynamic exposure of the Fama 
Table 3 Risk and performance analysis

\begin{tabular}{lllll}
\hline$J$ & 6 & 6 & 6 & SMI \\
$K$ & 3 & 6 & 12 & \\
\hline
\end{tabular}

Panel A: Risk and performance measures

\begin{tabular}{lllll}
\hline Geometric mean return (ann.) & $43.79 \%$ & $26.53 \%$ & $21.88 \%$ & $7.88 \%$ \\
Arithmetic mean return (ann.) & $53.80 \%$ & $32.00 \%$ & $25.25 \%$ & $9.66 \%$ \\
Volatility (ann.) & $38.27 \%$ & $29.73 \%$ & $23.81 \%$ & $18.05 \%$ \\
Sharpe ratio (ann.) & 0.9135 & 0.7356 & 0.7586 & 0.3165 \\
Correlation (SMI) & -0.2015 & -0.1213 & -0.0398 & - \\
Correlation (MSCI Bond Index) & 0.2046 & 0.1977 & 0.1901 & -0.0368 \\
Beta (SMI) & -0.4274 & -0.1999 & -0.0524 & 1.0000 \\
CAPM Alpha (monthly) & $3.76 \%$ & $2.30 \%$ & $1.77 \%$ & - \\
& $(0.0000)$ & $(0.0000)$ & $(0.0000)$ & \\
Two-Factor Alpha (monthly) & $3.76 \%$ & $2.30 \%$ & $1.73 \%$ & - \\
& $(0.0002)$ & $(0.0030)$ & $(0.0040)$ & \\
Skewness & 0.3609 & 0.0047 & 0.1181 & -0.7041 \\
Kurtosis & 3.8617 & 3.3038 & 4.5066 & 4.4368 \\
\hline
\end{tabular}

Panel B: Correlation between realized volatility of the SMI and momentum returns

\begin{tabular}{lllll}
\hline Monthly observations & 0.2659 & 0.2320 & 0.2453 & - \\
Quarterly observations & 0.4306 & 0.4198 & 0.3780 & - \\
Yearly observations & 0.7254 & 0.6899 & 0.7166 & - \\
\hline
\end{tabular}

Panel A of Table 3 reports some of the standard risk and performance measures for the three most profitable arbitrage portfolios $(J=6 / K=3, J=6 / K=6$, and $J=6 / K=12)$ and the Swiss Market Index (SMI, including dividend payments). Panel B exhibits the correlation coefficients between the realized volatility of the SMI and the momentum returns for monthly, quarterly, and yearly non-overlapping time periods. The results are based on the full sample period from 1994 to 2004. $p$-values are in parentheses

and French (1996) factors, nor by cross-sectional variability in stock's average returns, nor by exposure to industry factors. However, Chordia and Shivakumar (2002) show that the profits to momentum strategies can be explained by a set of lagged macroeconomic variables (i.e., dividend yield, default spread, yield on three-month T-bills, and term structure spread), and payoffs to momentum strategies disappear once stock returns are adjusted for their predictability based on these macroeconomic variables. These results provide a possible role for time-varying expected returns as an explanation for momentum payoffs.

To assess the riskiness of the arbitrage strategies, we first apply the following standard risk and performance measures: volatility, Sharpe ratio, correlation coefficient (with respect to the SMI and a broad Swiss bond index from MSCI), market beta (with respect to the SMI), Jensen's (CAPM) alpha and the alpha of a two-factor model including a market- and a value/growth-factor, skewness, and kurtosis. For purposes of brevity, we report the measures only for the three most profitable momentum strategies. The results are in Panel A of Table 3. The first row reproduces 
the geometric mean return over the full 11-year sample period as reported in Column 1 of Table 1 . The volatility of the momentum strategies is substantially higher than the volatility of the SMI. Still, due to the high strategy returns, the Sharpe ratios of all three strategies are substantially higher than that of the SMI. More important, the returns to all three arbitrage strategies are negatively correlated with the SMI, but positively correlated with the MSCI bond index. This finding strongly contrasts with that of Chordia and Shivakumar (2002) who find the returns to their momentum strategies to be positive only during expansionary periods while they are negative during recessions. ${ }^{11}$ The returns to our momentum strategies are substantially higher over the second sub-period where market returns are low and the marginal utility of returns is likely to be higher. Given the negative market betas of the momentum strategies (indicating that the loser stocks have higher betas on average than the winner stocks), it is not surprising that the (monthly) Jensen's alphas are very high and statistically significant at the $1 \%$ level. The alphas based on a two-factor model including the market beta with respect to the Swiss country portfolio and the HML-factor (the difference in returns between a portfolio of Swiss value and a portfolio of Swiss growth stocks) are of a similar magnitude and also statistically significant at the $1 \%$ level. The values for the skewness and the kurtosis of the momentum strategies are reasonable and, if anything, rather advantageous compared to the corresponding values for the SMI.

Panel B of Table 3 indicates that the momentum returns are positively correlated with the realized volatility of the SMI. Hence, we conclude that the returns to our momentum strategies are higher in volatile down markets than in less volatile up markets.

In a next step, we calculate risk-adjusted returns to the three most profitable strategies based on various risk models. We use a constant mean model, a market model with the SMI as market index, and, following Fama and French (1993), a two-factor model including the market beta with respect to the Swiss country portfolio and the HML-factor (the difference in returns between a portfolio of Swiss value and a portfolio of Swiss growth stocks) as provided by Kenneth French's Data Library. For the HML-factor, we use all four different characteristics provided by Kenneth French's Data Library to attribute stocks into either the value or growth portfolio: book-tomarket ratio, earnings-price ratio, cash earnings to price ratio, and dividend yield. However, the choice of this variable does not affect our conclusions and, hence, we only report the results based on the book-to-market ratio. As our sample is restricted to blue-chip stocks only, we omit the SMB-factor (the difference in returns between a portfolio of small-cap and a portfolio of large-cap stocks). ${ }^{12}$ All model parameters

\footnotetext{
${ }^{11}$ It is important to note that our finding of a negative correlation between momentum and SMI returns and the finding of Chordia and Shivakumar (2002) that momentum returns are positive only during expansionary periods while they are negative during recessions are two different, albeit related results. When applying the standard definition of two consecutive quarters with negative growth in real GDP (as compared to the same quarter in the previous year), we find two recessions (2001:4 to 2002:2 and 2003:1 to 2003:3) in the second and none in the first sub-period. In total, we find 6 quarters with a negative growth rate in the second and only one in the first sub-period.

${ }^{12}$ As there is still a huge difference in market capitalization between the largest and the smallest Swiss blue-chip stocks, we additionally test an alternative specification including the SMB-factor defined as the difference in returns between the Vontobel Small Cap Index and the SMI. However, the results are qualitatively similar as those for the CAPM and the two-factor model.
} 
(mean, market beta, and the coefficient on the HML-factor) are estimated in-sample over the complete sample period with data available. The corresponding look-ahead bias should not be of much concern, as this section is not about detecting momentum returns in real time, but about explaining them. In fact, Brandt (2005), for example, argues in his survey article that in-sample tests are not more prone to uncovering spurious effects and rather lead to more powerful tests than out-of-sample estimation.

The results are reported in Table 4. Panel A reports annualized (geometric) mean returns to the three most profitable arbitrage strategies $(J=6 / K=3, J=6$ / $K=6$, and $J=6 / K=12$ ) when the stock selection over the formation period is based on raw (i.e., not risk-adjusted) returns, but the holding period returns are the firm-specific residual return components. Similarly, Panel B reports the results when holding period returns are the systematic return components. For example, take the two-factor model given by

$$
R_{i t}=\alpha_{i}+\beta_{i} R_{M t}+\gamma_{i} H M L_{t}+\xi_{i t},
$$

where $R_{i t}$ denotes the simple raw return of stock $i$ in month $t$, and $R_{M t}$ and $H M L_{t}$ the market return and the value/growth factor in month $t$, respectively. Raw returns are then divided into the firm-specific residual return component $\xi_{i t}$ and the systematic return component given by the intercept and the market and HML factor. Alternatively (in the case of the market and the two-factor model), we define the firm-specific residual return component as $\alpha_{i}+\xi_{i t}$, but our results indicate no significant difference due to the different treatment of the intercept.

In general, the results in Columns 2 to 6 of Panel A indicate that the returns to our momentum strategies, while somewhat lower, are still substantial and range from $30.22 \%$ to $36.62 \%$ for the $J=6 / K=3$ strategy, from $17.38 \%$ to $21.25 \%$ for the $J=6 / K=6$ strategy, and from $14.23 \%$ to $17.62 \%$ for the $J=6 / K=12$ strategy. Moreover, the returns are very similar for all risk models. The results in Panel A show that by applying unconditional risk-adjustments, the returns to our momentum strategies are somewhat reduced, but remain very high. The residual components of unconditional risk models account for at least two thirds of the overall momentum profits, indicating that these models do not provide a sufficient explanation for the reported momentum payoffs. Consistently, the systematic return components (Panel B) are substantially lower and in general account for less than $50 \%$ of the arbitrage strategy returns reported in Column 1.

In the spirit of Chordia and Shivakumar (2002), we also repeat the above analysis for conditional risk models. Specifically, we investigate whether the profits to our arbitrage momentum strategies can be explained by a set of lagged macroeconomic variables and, hence, time-varying expected returns are a possible explanation for the documented momentum returns. The predicted stock return is the one-period-ahead forecast from the following regression

$$
R_{i t}=\alpha_{i}+\beta_{i} \boldsymbol{X}_{t-1}+\xi_{i t},
$$

where $\boldsymbol{X}_{t-1}$ denotes a vector of lagged predictive variables. For the same reason as before, but in contrast to Chordia and Shivakumar (2002), the parameters of the model are estimated in-sample over the complete sample period with data available. 


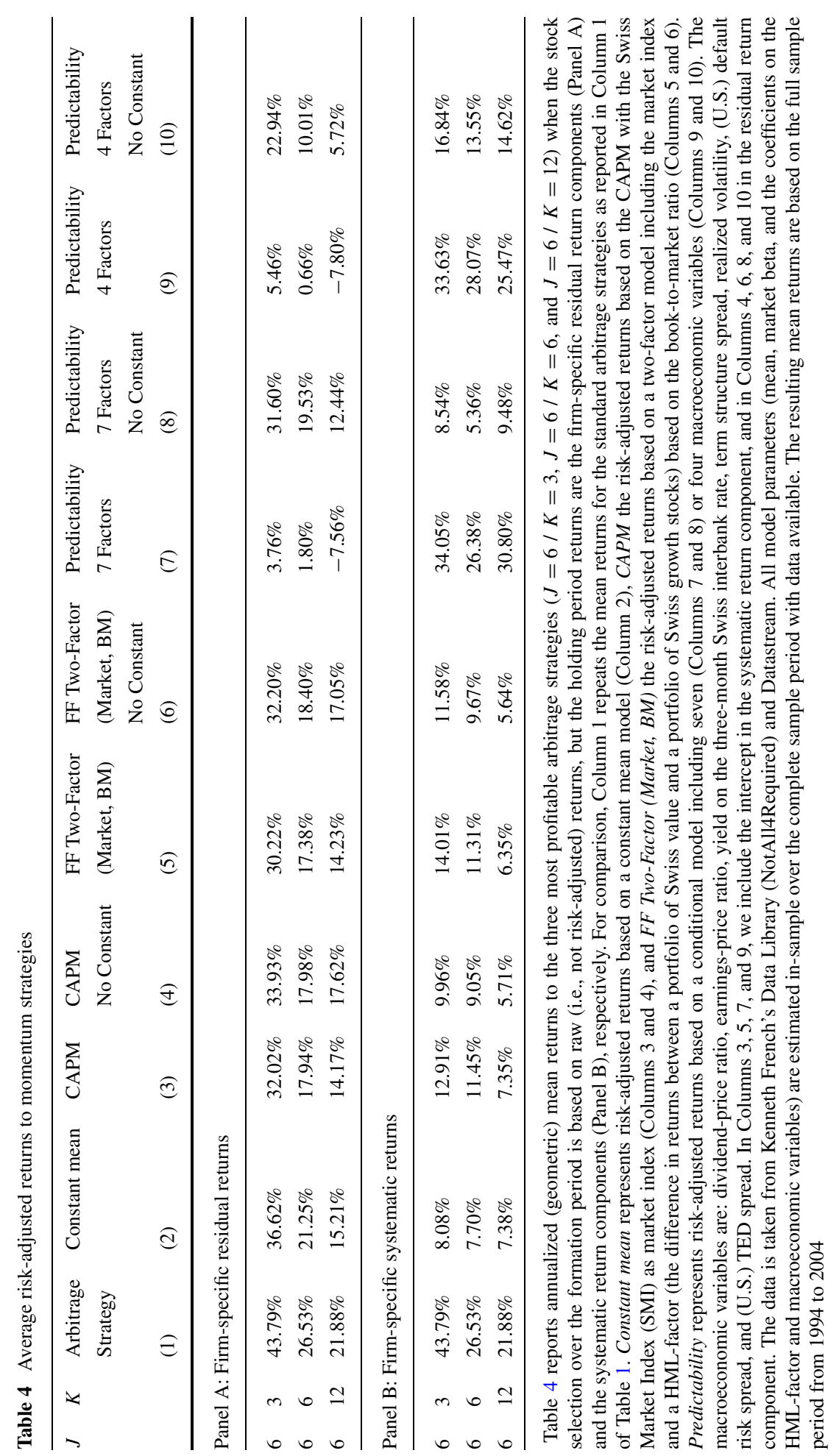


These parameter estimates are then used to obtain the one-month-ahead predicted return for each stock and each month $t$. Raw returns are divided into the firm-specific residual return component $\xi_{i t}$ and the systematic return component given by the intercept and the last realizations of the predictive variables. Alternatively, we define the firm-specific residual return component as $\alpha_{i}+\xi_{i t}$. Chordia and Shivakumar (2002) exclude the intercept from the predicted portion of the model. They argue that the estimated intercept may lead them to control for cross-sectional differences in average returns that are unrelated to the business cycle. They note, however, that their results are essentially unchanged if the intercept is included in the predicted component of returns. Our results in Table 4 suggest that the treatment of the intercept has a non-neglecting impact on the results.

The variables we use in this prediction are standard macroeconomic variables known to predict market returns. These are the dividend-price ratio, earnings-price ratio, yield on the 3-month Swiss interbank rate, term structure spread, realized volatility, (U.S.) default risk spread, and (U.S.) TED spread. The dividend-price ratio/earnings-price ratio is measured as the sum of dividends/earnings paid on the Swiss stock market index over the previous year, divided by the current level of the index. The term structure spread is the difference between the nominal yield on 10year Swiss government bonds and the nominal 3-month Swiss interbank rate. Realized stock market volatility is calculated as suggested by Goyal and Santa-Clara (2003), using within-month daily return data for each month. The US default risk spread is formed as the difference in annualized yields of Moody's Baa and Aaa rated bonds. Finally, the US TED spread is the difference between the three-month Eurodollar rate and the yield on the 3-month T-bill.

Table 4 reports the results based on a model including all seven predictive variables and the regression specification suggested by Chordia and Shivakumar (2002) including only the dividend-price ratio, the yield on the three-month T-bill, the term structure spread, and the default risk spread. Despite the fact that the predictive power of these regression models is very modest (the average coefficient of determination is only slightly above 4\%), our results suggest that the predicted part of the returns can explain a large part of the observed momentum phenomenon. This is especially true when the intercept is part of the systematic return component. In this case, the systematic return components explain most of the momentum payoffs (sometimes even more than $100 \%$ ). If the intercept is part of the residual return component, however, the explanatory power of the lagged predictive variables is considerably lower, but remains at quite a high level. As compared to the unconditional risk models, these results reveal that the predicted part of returns can explain a large part of the observed momentum phenomenon. This finding indicates that momentum payoffs can be attributed to cross-sectional differences in conditionally expected returns.

\subsection{Market inefficiencies}

A large body of literature tries to explain the profitability of momentum strategies by market inefficiencies and irrational investors. Chan et al. (1996, 1999), for example, conjecture that momentum returns might be driven by investor underreaction to firm-specific information. Hong et al. (2000) test empirically whether momentum 
reflects underreaction due to a gradual diffusion of firm-specific information by testing the effect of firm size and analyst coverage on the profitability of momentum strategies. Most important, they find that momentum returns decline sharply with market capitalization and analyst coverage. Additionally, there is a strong asymmetry in that the effect of analyst coverage is much more pronounced for stocks that are past losers than for stocks that are past winners. In other words, they find low-coverage stocks to react more sluggishly to bad than to good news. Summarizing, their findings are consistent with their hypothesis that momentum is caused by a gradual diffusion of information and, hence, should not be present or very small for large-cap firms and/or firms with high analyst coverage where information is presumably released to all market participants by the same time. However, our results contradict those of Hong et al. (2000) as our sample is restricted to large-cap stocks with presumably high analyst coverage. Nevertheless, we find very high returns to our momentum strategies.

Jegadeesh and Titman (2001) test three alternative hypotheses: (1) underreaction, (2) overreaction and price correction, and (3) the risk-based explanation put forth by Conrad and Kaul (1998). The behavioral models of Barberis et al. (1998), Daniel et al. (1998), and Hong and Stein (1999), and the risk-based explanation of Conrad and Kaul (1998) make diametrically opposed predictions about the returns of past winner stocks and loser stocks over the period following the original holding period. The behavioral models imply that the holding period abnormal returns arise because of delayed overreaction to information that pushes the prices of the winner stocks (loser stocks) above (below) their long-term values. ${ }^{13}$ These models predict that in subsequent time periods, when the stock prices of the winner and loser stocks revert to their fundamental values, the returns of the loser stocks should exceed the returns of the winner stocks. In contrast, Conrad and Kaul (1998) suggest that the higher returns of the winner stocks in the holding period represent their unconditional expected rates of return and thus predict that the returns of the momentum portfolio will be positive on average in any post-formation period. Jegadeesh and Titman (2001) examine the returns of the winner and loser stocks over a post-holding period of 5 years. Consistent with the behavioral theories but inconsistent with the Conrad and Kaul (1998) hypothesis, they find the cumulative average returns of their long/short-portfolios over months 13 to 60 to be negative. However, when size-based sub-samples are constructed, the evidence for return reversals is weaker for large firms. In addition, Jegadeesh and Titman (2001) find the return reversals to be substantially weaker in the later 1982 to 1998 sub-period. The return reversals are especially weak for the second sub-period and large firms when alphas from a Fama and French (1993) three-factor model are used instead of raw returns.

To shed some further light on these issues and test the three competing hypotheses for our more recent sample period comprising exclusively Swiss blue-chip stocks, we replicate and extend the analysis of Jegadeesh and Titman (2001). Specifically, based on a rolling event study analysis, we examine the cumulative average return differences between the winner and the loser stocks following the initial formation date. As the theoretical models do not offer any guidance regarding the length of the

\footnotetext{
${ }^{13}$ For more information regarding the underlying behavioral biases, we refer to Jegadeesh and Titman (2001) and Hirshleifer (2001). 
relevant post-holding period over which return reversals are expected to occur, we follow Jegadeesh and Titman (2001) and use a post-holding period of 5 years. ${ }^{14}$ As argued by Jegadeesh and Titman (2001), the three hypotheses imply different return patterns over the post-holding period: (1) The underreaction hypothesis predicts that prices adjust slowly to information, but once the information is fully incorporated in prices, there is no further predictability in stock returns (i.e., post-holding period returns are expected to be zero). (2) The overreaction and price correction hypothesis predicts that over the post-holding period, when the stock prices of the winner and loser stocks revert to their fundamental values, return differences between the winner and the loser stocks should be negative. (3) Finally, the risk-based explanation of Conrad and Kaul (1998) predicts that the returns to the momentum strategies are positive on average in any post-formation period as the higher returns of the winner stocks over the holding period represent their unconditional expected rates of return.

Figures $3 b$ and $3 d$ show the cumulative average return differences between the winner and the loser stocks of the $J=6 / K=6$ strategy over a 12-months holding and a 60-months post-holding period. In addition to raw returns, Figs $3 \mathrm{~b}$ and $3 \mathrm{~d}$ also include various cumulative average risk-adjusted return differences, based on the same risk models as in Table 4. ${ }^{15}$ Again, all model parameters (mean, market beta, the coefficient on the HML factor, and the parameters of the conditional risk model) are estimated in-sample over the complete sample period with data available. Figures $3 \mathrm{~b}$ and $3 \mathrm{~d}$ indicate that the cumulative average return differences between the winner and the loser stocks reach a first peak after 12 months, i.e., at the end of the holding period. Over the following 24 months, cumulative average return differences first decrease and then increase again to reach the maximum value after 36 months. Finally, over the subsequent 36 months, the results reveal a dramatic reversal of the cumulative average return differences. Hence, our results confirm those of Jegadeesh and Titman (2001) and are consistent with the overreaction and price correction hypothesis, but inconsistent with the risk-based hypothesis of Conrad and Kaul (1998). This conclusion is robust to unconditional risk-adjustments: Irrespective of the constant mean model, the market model, or the two-factor model, cumulative average return differences between the winner and the loser stocks are closely tracked by the respective residual return components (Fig. 3b), but not the systematic return components (Fig. 3d). However, the systematic return components of the conditional risk model closely match the observed behavior of the cumulative average return differences between the winner and the loser stocks. In other words, cross-sectional differences in conditionally expected returns are able to replicate most of the post-holding period behavior of the winner and loser stocks, respectively. Stock market predictability and time-varying expected returns are therefore a possible explanation for the momentum payoffs.

\footnotetext{
${ }^{14}$ Recent studies of initial public offerings and seasoned equity offerings find evidence of underperformance for up to five years after the events (e.g., see Loughran and Ritter 1995; Spiess and Affleck-Graves 1995).

${ }^{15}$ In Fig. 3, we only display the results for the HML-factor that is based on the book-to-market ratio. The results for the earnings-price ratio, cash earnings to price ratio, and dividend yield are basically identical.
} 
(a) Pre-Formation Period (Residual) Returns

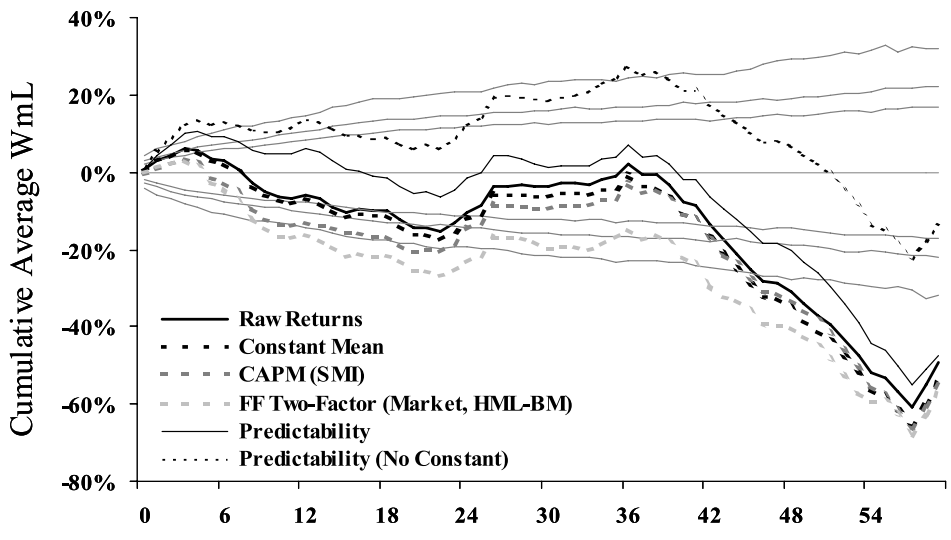

Number of Months

\section{(b) Holding and Post-Holding Period (Residual) Returns}

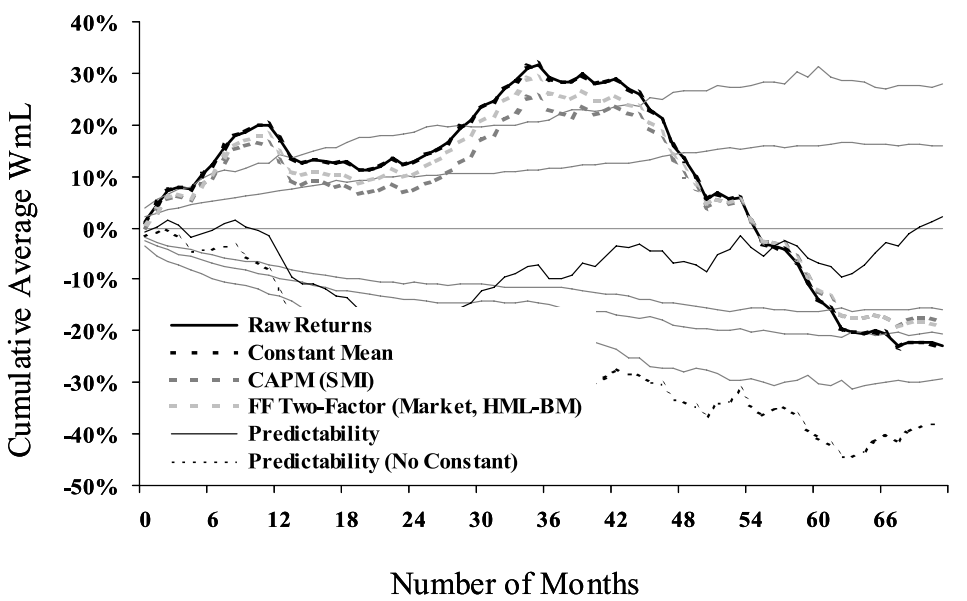

Fig. 3 Pre-formation and post-holding period residual and systematic returns. Figure 3 displays cumulative average return differences between the winner and the loser stocks over different time periods around the event dates (end of formation periods). The winner and loser stocks correspond to the $J=6 / K=6$ strategy. A positive (negative) slope indicates that the monthly returns of the winner stocks are higher (lower) than the monthly returns of the loser stocks. In this rolling event-study analysis, the length of the pre-formation period is 60 months. The formation period of 6 months is followed by the one-month lag and the (extended) holding period of 12 months. Finally, the length of the post-holding period is 60 months. The $1 \% / 5 \% / 10 \%$ confidence intervals are obtained by a Monte Carlo analysis that picks stocks randomly from the corresponding investment universe (2000 simulations). Constant mean represents risk-adjusted returns based on a constant mean model, $C A P M(S M I)$ the risk-adjusted returns based on the market model with the SMI as market index, and FF Two-Factor (Market, HML-BM) the risk-adjusted returns based on a two-factor model including the market index and the HML-factor (the difference in returns between a portfolio of Swiss value and a portfolio of Swiss growth stocks) based on the book-to-market ratio as provided by Kenneth French's Data Library (NotAll4Required). Predictability represents risk-adjusted returns based on a conditional model including seven macroeconomic variables (dividend-price ratio, earnings-price ratio, yield on the three-month Swiss interbank rate, term structure spread, realized volatility, (U.S.) default risk spread, and (U.S.) TED spread). The intercept is either part of the systematic return component (Predictability) or the residual return component (Predictability (No Constant)). All model parameters (mean, market beta, and the coefficient on the HML-factor and the macroeconomic variables) are estimated in-sample over the complete sample period with data available 
(c) Pre-Formation Period (Systematic) Returns

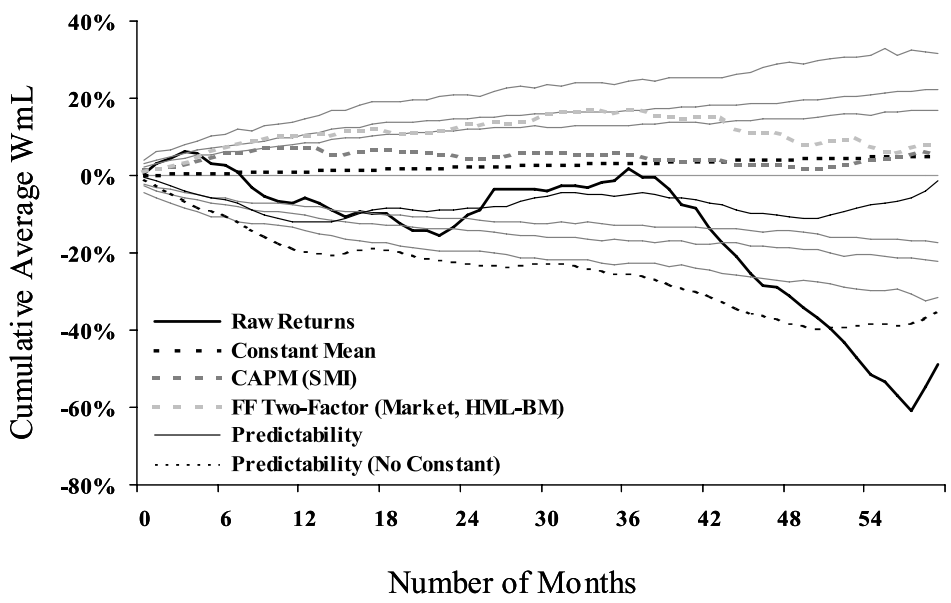

(d) Holding and Post-Holding Period (Systematic) Returns

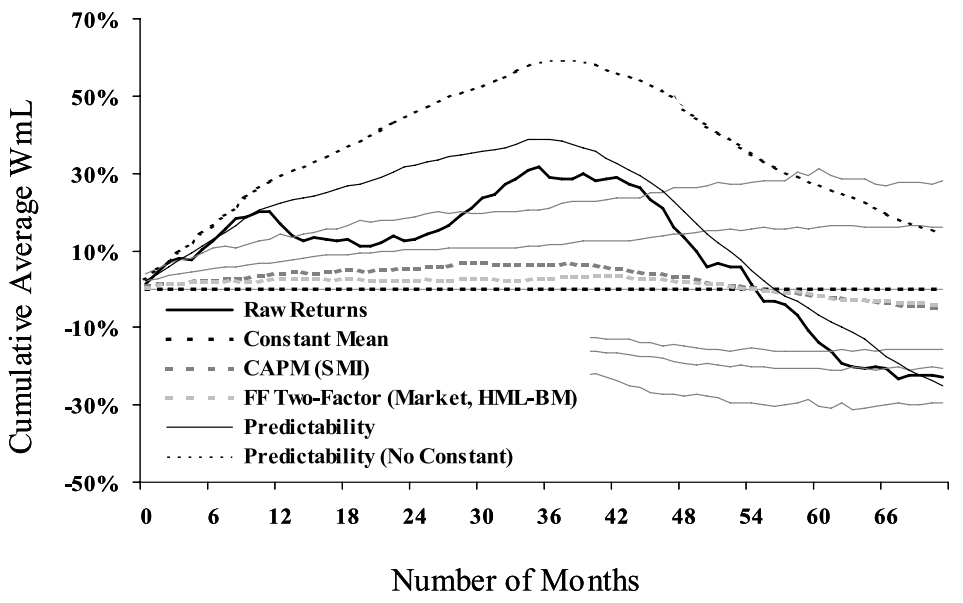

Fig. 3 (Continued)

Finally, we also investigate cumulative average return differences between the winner and the loser stocks of the $J=6 / K=6$ strategy prior to the formation period. Figure 3 a shows the results for raw and risk-adjusted returns for a 60 -months pre-formation period; Fig. $3 \mathrm{c}$ the results for raw returns and the systematic return components. Cumulative average return differences are substantially negative over the complete 60-months pre-formation period, indicating that the loser stocks perform better than the winner stocks on average. The majority of this "contrarian effect" occurs over the last 24 months before the formation period. In contrast to the (post-) holding period, neither unconditional nor conditional risk models can satisfactorily explain this price behavior prior to the formation period. To our knowledge, there is no other study that documents and discusses such a pre-formation price behavior of the winner and loser stocks. 


\section{Conclusion}

This study measures the profitability of feasible momentum strategies for the Swiss stock market designed for a minimization of trading costs. Interestingly, our simple price momentum strategies restricted to Swiss blue-chip stocks experience returns which are comparable to those from momentum strategies allowed to invest in all stocks listed at NYSE, AMEX, and NASDAQ. Specifically, depending on the length of the formation and holding period, the arbitrage strategies experience annualized geometric mean returns between $9.19 \%$ and $43.79 \%$ p.a. We find this high profitability of our feasible momentum strategies to be robust to splitting the 11-year sample period into sub-periods of equal length, where the first is characterized by a bull and the second by a bear market. Moreover, the returns to our momentum strategies are higher during volatile bear markets, when the marginal utility of returns is likely to be high. Hence, the risk profile of our momentum strategies makes them particularly advantageous from a portfolio diversification point of view. Several other robustness checks show that these results do not seem to be caused by some few months with extremely high returns or a few individual stocks in the sample. They are also robust to omitting the annual rebalancing or restricting the strategies to invest more than one investment cohort into the same stock. Finally, when considering the effect of transaction costs, albeit in a very simplistic way, the results suggest that the profitability of our momentum strategies remains high for reasonable estimates of transaction costs associated with institutional trading in blue-chip stocks.

Although the high profits associated with momentum strategies have been well accepted, the source of these profits and the interpretation of the evidence are widely debated. We apply various risk measures but find our strategy returns to be only slightly reduced on a risk-adjusted basis. However, using a set of lagged macroeconomic variables to predict one-month-ahead returns, our results suggest that the predicted part of returns can explain a large part of the observed momentum phenomenon. Hence, cross-sectional differences in conditionally expected returns are able to replicate most of the post-holding period behavior of the winner and loser stocks, respectively.

We also replicate the analysis of Jegadeesh and Titman (2001) and investigate the strategy returns over a 60-months post-holding period to test the (1) underreaction hypothesis, (2) the overreaction and price correction hypothesis, and (3) the risk-based explanation of Conrad and Kaul (1998). Our results confirm those of Jegadeesh and Titman (2001) and are consistent with the overreaction and subsequent price correction hypothesis, while inconsistent with the risk-based hypothesis of Conrad and Kaul (1998). However, when we consider the residual and systematic return components based on our conditional risk model separately, we find that the systematic return component closely matches the observed behavior of the cumulative average return differences between the winner and loser stocks. Again, this result indicates that cross-sectional differences in conditionally expected returns are able to replicate most of the post-holding period behavior of the winner and loser stocks, respectively.

Whether the findings of this study can be generalized to other stock markets is an interesting subject for future research. In a follow-up paper, we are testing similar strategies for other major European stock markets and the U.S. 
Acknowledgements We thank an anonymous referee, Manuel Ammann (the editor), Thomas Portmann, Heinz Zimmermann, Bank Sarasin \& Cie (Matthias Leuenberger, Martin Schreier and particularly Andreas Kessler), the participants of the 2004 doctoral colloquium in finance of the University of Basel at Engelberg, the 2004 European Financial Management Association conference, and a 2004 seminar of the Swiss CFA society for helpful suggestions and remarks. Parts of this research were undertaken while Schmid was a visiting scholar at New York University's Leonard N. Stern School of Business; he acknowledges financial support from the Swiss National Science Foundation (SNF) and the Freiwillige Akademische Gesellschaft (FAG). All errors remain our responsibility.

\section{References}

Bacmann, J.-F., Dubois, M.: La performance des stratégies contraires et momentum sur le marché Suisse. Financ. Mark. Portf. Manag. 14, 252-266 (2000)

Ball, R., Kothari, S.P., Shanken, J.: Problems in measuring portfolio performance: An application to contrarian investment strategies. J. Financ. Econ. 38, 79-107 (1995)

Barberis, N., Shleifer, A., Vishny, R.: A model of investor sentiment. J. Financ. Econ. 49, 307-343 (1998)

Brandt, M.W.: Portfolio choice problems. In: Ait-Sahalia, Y., Hansen, L.P. (eds.) Handbook of Financial Econometrics. (2005, forthcoming)

Carhart, M.M.: On persistence in mutual fund performance. J. Finance 52, 57-82 (1997)

Chakrabarty, B., Trzcinka, C.: Momentum: Does the database make a difference?. J. Financ. Res., 441-462 (2006)

Chan, K.C.L., Jegadeesh, N., Lakonishok, J.: Momentum strategies. J. Finance 51, 1681-1713 (1996)

Chan, K.C.L., Jegadeesh, N., Lakonishok, J.: The profitability of momentum strategies. Financ. Analysts J. 55, 80-90 (1999)

Chen, H.-L., Jegadeesh, N., Wermers, R.: The value of active mutual fund management: An examination of the stockholdings and trades of fund managers. J. Financ. Quant. Anal. 35, 343-368 (2000)

Chopra, N., Lakonishok, J., Ritter, J.R.: Measuring abnormal performance: Do stocks overreact?. J. Financ. Econ. 31, 235-268 (1992)

Chordia, T., Shivakumar, L.: Momentum, business cycle, and time-varying expected returns. J. Finance 57, 985-1019 (2002)

Conrad, J., Kaul, G.: An anatomy of trading strategies. Rev. Financ. Stud. 11, 489-519 (1998)

Daniel, K., Hirshleifer, D., Subrahmanyam, A.: Investor psychology and security market under- and overreactions. J. Finance 53, 1839-1886 (1998)

DeBondt, W.M.F., Thaler, R.: Does the stock market overreact?. J. Finance 40, 793-805 (1985)

DeBondt, W.M.F., Thaler, R.: Further evidence on investor overreaction and stock market seasonality. J. Finance 42, 557-581 (1987)

Fama, E.F., French, K.R.: Common risk factors in the returns on stocks and bonds. J. Financ. Econ. 33, 3-56 (1993)

Fama, E.F., French, K.R.: Multifactor explanations of asset pricing anomalies. J. Finance 51, 55-84 (1996)

Goyal, A., Santa-Clara, P.: Idiosyncratic Risk Matters!. J. Finance 58, 975-1007 (2003)

Grinblatt, M., Moskowitz, T.J.: Predicting stock price movements from past returns: The role of consistency and tax-loss selling. J. Financ. Econ. 71, 541-579 (2004)

Grundy, B.D., Martin, J.S.: Understanding the nature of the risks and the source of the rewards to momentum investing. Rev. Financ. Stud. 14, 29-78 (2001)

Hirshleifer, D.: Investor psychology and asset pricing. J. Finance 56, 1533-1597 (2001)

Hong, H., Lim, T., Stein, J.C.: Bad news travels slowly: Size analyst coverage, and the profitability of momentum strategies. J. Finance 55, 265-296 (2000)

Hong, H., Stein, J.C.: A unified theory of underreaction, momentum trading, and overreaction in asset markets. J. Finance 54, 2143-2184 (1999)

Jegadeesh, N.: Evidence of predictable behavior of security returns. J. Finance 45, 881-898 (1990)

Jegadeesh, N., Titman, S.: Returns to buying winners and selling losers: Implications for stock market efficiency. J. Finance 48, 65-91 (1993)

Jegadeesh, N., Titman, S.: Overreaction, delayed reaction, and contrarian profits. Rev. Financ. Stud. 8, 973-993 (1995)

Jegadeesh, N., Titman, S.: Profitability of momentum strategies: An evaluation of alternative explanations. J. Finance 56, 699-720 (2001)

Korajczyk, R., Sadka, R.: Are momentum profits robust to trading costs?. J. Finance 59, 1039-1082 (2004) 
Lehmann, B.N.: Fads, martingales, and market efficiency. Q. J. Econ. 60, 1-28 (1990)

Lesmond, D.A., Schill, M.J., Zhou, C.: The illusory nature of momentum profits. J. Financ. Econ. 71, 349-380 (2004)

Lo, A.W., MacKinlay, A.C.: When are contrarian profits due to stock market overreaction?. Rev. Financ. Stud. 3, 175-205 (1990)

Loughran, T., Ritter, J.R.: The new issues puzzle. J. Finance 50, 23-51 (1995)

Rouwenhorst, K.G.: International momentum strategies. J. Finance 53, 267-284 (1998)

Schiereck, D., DeBondt, W., Weber, M.: Contrarian and momentum strategies in Germany. Financ. Analysts J. 55, 104-116 (1999)

Spiess, D.K., Affleck-Graves, J.: Underperformance in long-run stock returns following seasoned equity offerings. J. Financ. Econ. 38, 243-267 (1995)

Womack, K.L.: Do brokerage analysts' recommendations have investment value?. J. Finance 51, 137-167 (1996)

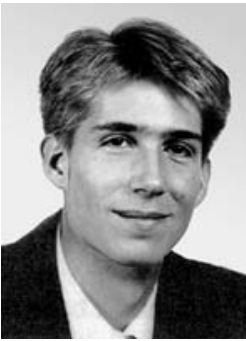

David M. Rey studied economics with an emphasis in finance at the Universities of Bern, Lancaster (UK), and St. Gallen (HSG), where he also received his doctorate in finance. He works as a research assistant at the Wirtschaftswissenschaftliches Zentrum (WWZ) of the University of Basel. His main research interests are in the areas of asset pricing and asset management.

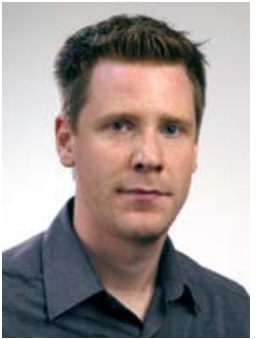

Markus M. Schmid is a lecturer of finance at the University of St. Gallen (HSG), Switzerland. Prior to his current appointment he was a post-doctoral research scholar at Leonard N. Stern School of Business, New York University. Markus Schmid holds a doctoral degree in finance from the University of Basel. His research interests are in the field of empirical corporate finance, corporate governance, and alternative investments. 